\title{
Direksiyon Aksonlarının Statik Hasar Analizi
}

\author{
${ }^{* 1}$ Murat Makaracı, Süleyman Demir, Onur Bahçacı
}

*1 Kocaeli Üniversitesi, Mühendislik Fakültesi, Makine Mühendisliği Bölümü, Umuttepe-Kocaeli *Corresponding author: Address: Faculty of Engineering, Department of Mechanical Engineering Kocaeli University, 41380, Kocaeli TURKEY. E-mail address: mmakaraci@kocaeli.edu.tr, Phone: +90262 3033426

\section{Özet}

Direksiyon mafsalı, direksiyon sistemini yürüyen aksama bağlayan, ön takımı taşıyan ve aracın yönlendirilmesini sağlayan parçadır. Bu çalışmada direksiyon mafsalının statik yük analizleri yapılarak, parçanın hasara karşı güvenilirliği araştııılmıştır. Araştırmada direksiyon mafsalının 3 boyutlu geometrik modeli, diğer akson geometrilerinden farklı olarak tasarlanmıştır. Yapılan bu çalışmada kullanılan diğer aksonlardan farklı olarak geometride yüzeyleri süpüren radyus ölçüleri, otomobil lastik bağlantı kısımlarının et kalınlıkları ve rotil başlarının bağlantısının yapıldığı mesnetlerin et kalınlıkları üzerinde uygun değişiklikler yapılmıştır. Literatür araştırmasından direksiyon mafsalının en çok hasara uğradığı çalışma koşulları tespit edilmiştir. Bu çalışmada direksiyon mafsalının bu zorlu çalışma koşullarındaki gerilme analizleri sonlu elemanlar metodu kullanılarak yapılmıştır. Sonuç olarak tasarımı yapılan direksiyon mafsalının bu çalışma koşullarında güvenli olduğu ortaya çıkmıştır.

Anahtar kelimeler: Direksiyon, akson, hasar, CAD, FEM

\begin{abstract}
Steering knuckle is a part which connects the steering system to the tires to carry the front bearing system for vehicle operation. In this study, statical load analyses are conducted for reliability investigation against damage. A different 3D design of knuckle is considered where surface radius, vehicle-tire connection thickness and knuckle connection thickness were changed in accordance with present model. From literature, working conditions for maximum damage are identified and the finite element model is used to analyse the steering knuckle. Conclusively, newly designed steering knuckle is found to be reliable under these statics conditions.
\end{abstract}

Key words: Steering, knuckle, failure, CAD, FEM

\section{Giriş}

Direksiyon aksonu, araç direksiyon sisteminin önemli parçalarından biridir. Kompleks çalışma koşullarında aksonun güvenilirliği direkt olarak araçların ve insanların güvenliğini etkiler. Direksiyon aksonu bir yandan yolun etkilerini ve lastiklerde oluşabilecek herhangi bir tehlike durumunun sorunluluğunu üstlenirken diğer yandan direksiyon simidine uygulanan yönlendirme kuvvetini de ileterek aracın yönlendirilmesini sağlar. Bu durumda aksonun yüksek kuvvetlerden oluşabilecek sorunları dayanabilecek statik, yorulma mukavemetine ve sistemin hareketi nedeniyle oluşabilecek titreşimleri karşılayabilecek güvenilirliğe sahip olması gerekir. Sonuç olarak akson tasarımında asıl önemli olan kısım, gerilme ve yorulma analizleridir. Tablo 1.1 'de de tasarım parametreleri verilmiştir. $\mathrm{Bu}$ araştırmada akson Şekil 1'de gösterildiği gibi Solidworks yazılımı ile modellenmiştir. Ansys ve Solidworks Simulation yazılımı kullanılarak aksonun statik analizleri incelenmiştir. 

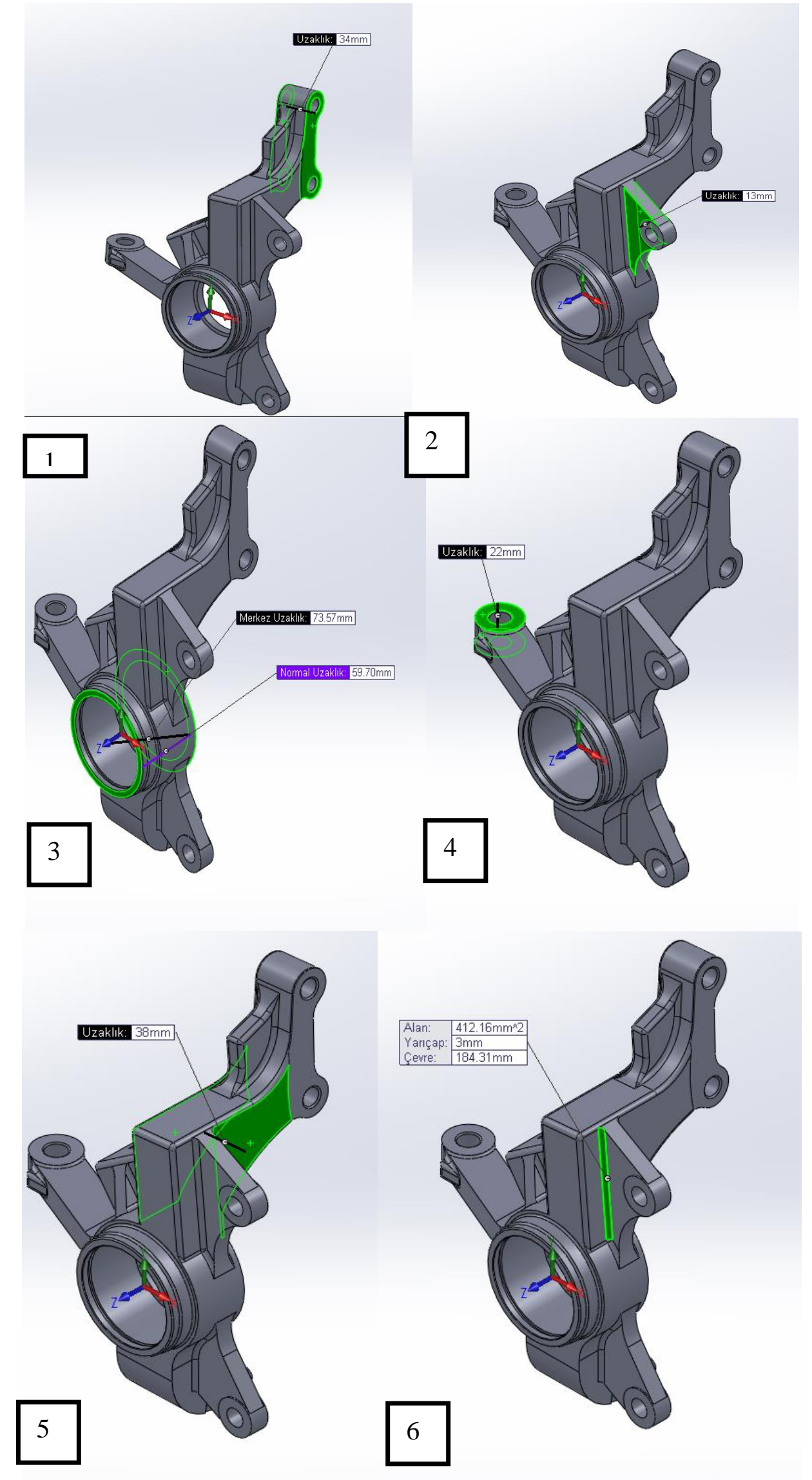

Şekil 1. Aksonun CAD modeli 
Tablo 1.1 Geometri parametreleri

\begin{tabular}{|lc|c|}
\hline \multicolumn{2}{|c|}{ Tanımlamalar } & Parametre (mm) \\
\hline Amortisör bağlantı kulağı & $(1)$ & 34 \\
\hline Şasi bağlantı kulakçı̆̆ı & $(2)$ & 13 \\
\hline Tekerlek bağlantısı mesnedi & $(3)$ & 59,7 \\
\hline Rot başı bağlantı et kalınlığı & $(4)$ & 22 \\
\hline Amortisör bağlantısı kolu et kalınlığı & $(5)$ & 38 \\
\hline Geometri yarıçapları & $(6)$ & 3 \\
\hline
\end{tabular}

\section{Direksiyon Aksonunun Sonlu Eleman Modellemesi}

Bir araçta her bir yönde bir tane olmak üzere iki tane akson bulunur. Bunlar direksiyon aksina bağlıdır. Her bir aksonun kulağında onların rotillerle ön aksa bağlanmasını sağlayan silindirik delikler bulunur. Direksiyon aksonları ön tekerlerde bulunmaktadır. Bunun sebebi, otomobilin yönlendirilmesini sağlamak için akson doğrultusu etrafında kesin dönme açıları oluşturabilmektir. Karşılaştırılan akson geometrisi ve sonlu elemanlar modeli Şekil 3 de gösterildiği gibidir.

Kullanılan akson ikinci dereden dörtyüzlü elemanlar ile 'mesh' adı verilen küçük elemanlara dönüştürülmüştür. Şekil 3'de görüldüğü gibi akson 25038 elemana, bu elemanlar 42074 düğümden oluşmaktadır. Aksonda kullanılan malzeme isimli küresel dökme demirdir. Kullanılan döküm malzemenin mekanik özellikleri Tablo 2.1'de verilmiştir.

Tablo 2.1 QT500-7 malzemenin mekanik özellikleri

\begin{tabular}{|l|l|}
\hline Elastik modülü $(\mathrm{GPa})$ & 160 \\
\hline Poisson oranı & 0,28 \\
\hline Yoğunluk $\left(\mathrm{kg} / \mathrm{m}^{3}\right)$ & $7,3 \cdot 10^{3}$ \\
\hline Akma mukavemeti $(\mathrm{MPa})$ & 320 \\
\hline
\end{tabular}

Aksonun sınır koşulları şu şekildedir: Her çalışma koşullarına karşılık gelen yükler lastik ve zemin arasındaki temas noktasından uygulanmıştır. Yönlendirme rotu ve aksonun birleşme yeri sabit nokta olarak kabul edilen kısımlardır. Şekil 2'de amortisör ile helezon bağlantısının yapıldığı kısım tarafsız eksene göre $\mathrm{x}$ ve $\mathrm{z}$ eksenlerinde sabit $\mathrm{y}$ ekseninde ise 5 mm'lik bir deplasman ile sınırlandırılmıştır [2].

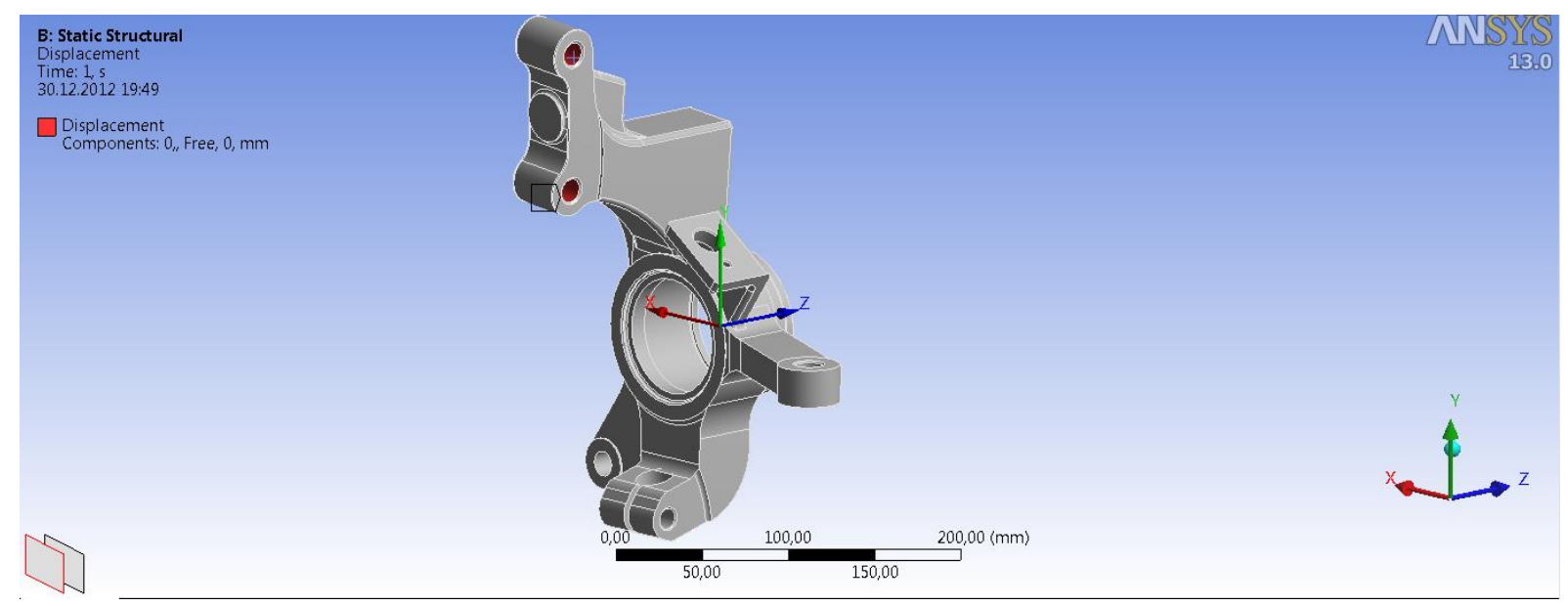

Şekil 2. Amortisör ve helezonun bağlantı kısımlarında sınır koşullarının belirlenmesi

Maksimum yük koşullarında aracın toplam ağırlığı 1607,3 kg'dır. Ön aks yükü 829,5 kg, arka aks yükü 777,8 kg'dır. Dingil açıklığı L = $2606 \mathrm{~mm}$, iki tekerlek arasındaki mesafe $1470 \mathrm{~mm}$, aksonun dış yüzü ile tekerlek merkezi arasındaki uzaklık L' = 6,9 mm'dir. Lastiğin dönme yarıçapı $\mathrm{R}=294 \mathrm{~mm}$ dir. Lastik modeli ise 205 / 50R16'dır. Tam yükte ağırlık merkezi yüksekliği hg =680 mm'dir[4]. 

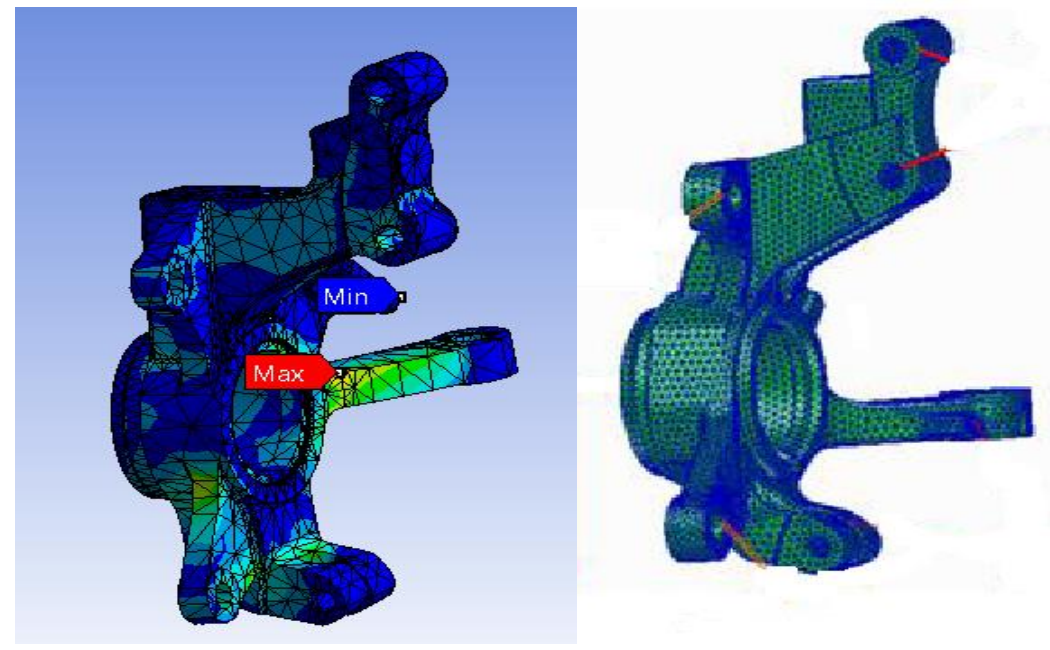

Şekil 3. Aksonun sonlu elemanlar modelinin oluşturulması

\section{3. Çalışma Koșulları Analizi}

Yüklü durumda hareket eden tekerlekler göz önüne alındığında akson üç tehlikeli koşulda bulunabilir.
A ) Darbeli yük Koşulları
B ) Acil fren koşulları
C ) Kaygan zemin koşulları

Bu çalışmada bu üç koşulun sınır durumları analiz edilerek direksiyon aksonunun mukavemeti ile ilgili veri toplanmıştır.

\subsection{Darbeli Yol Koşulları}

$\mathrm{Bu}$ koşul darbeli yükte tekerleklerin durumunu belirtir. Yani dinamik yük faktörü maksimumdur. $\mathrm{Bu}$ durumda aksona yalnızca normal kuvvet olan $\mathrm{Fz}$ etki eder. Şekil 4'da gösterilmiştir.

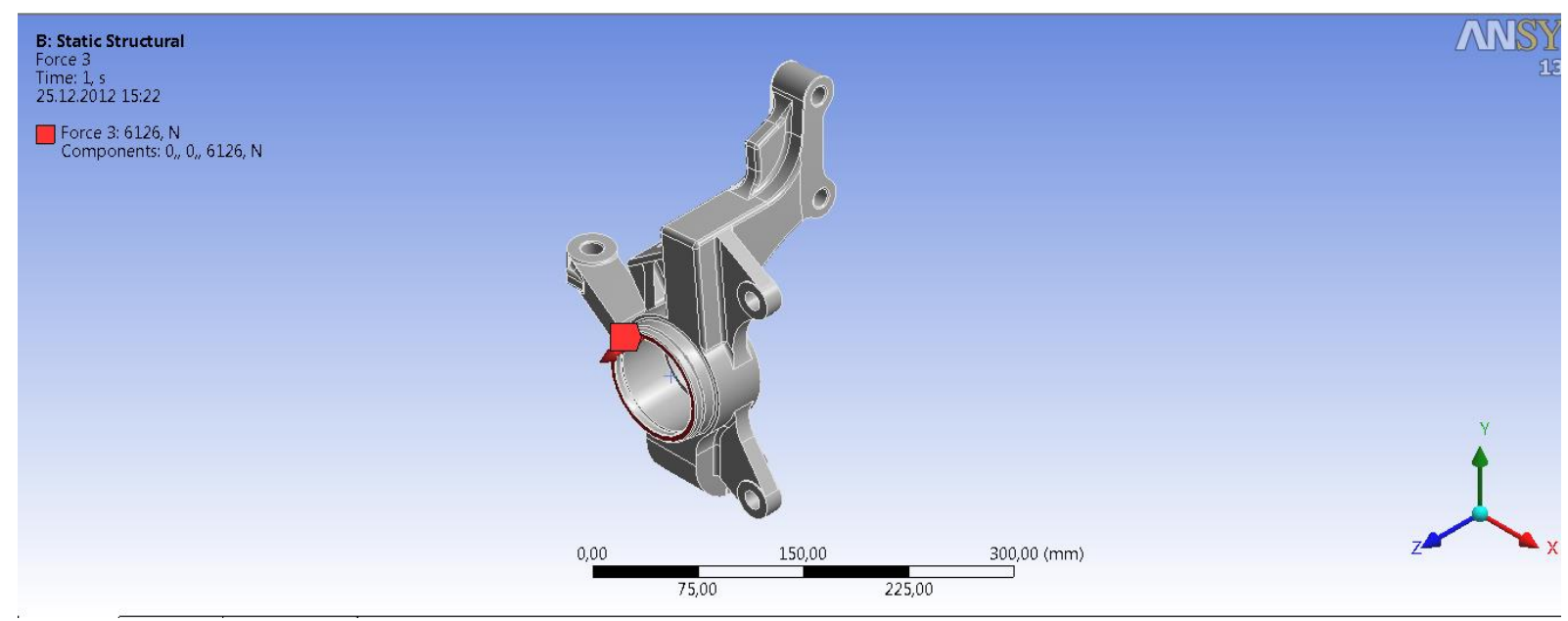

Şekil 4. Normal kuvvet $\left(\mathrm{F}_{\mathrm{z}}\right)$ uygulaması

\subsection{Acil Frenleme Koşulları}

$\mathrm{Bu}$ koşullarda akson normal kuvvet $\mathrm{Fz}$ ile lastiklerden dingil üzerine gelen kuvvet olan teğetsel kuvveti Fx'i de taşır. Şekil 5'de gösterildiği gibi, bu durumda sistem her iki yükü de beraber taşımaktadır. Bu da ön aksonun yeniden dağıttığı ağırlık neticesinde dikey yönde bir eğilme momentine neden olur. Ayrica yatay yöndeki ataletlerden kaynaklanan momentler de ortaya çıkar. Acil frenleme momenti akson üzerine gelebilecek maksimum değerde oluşabilecek momenttir [3]. 


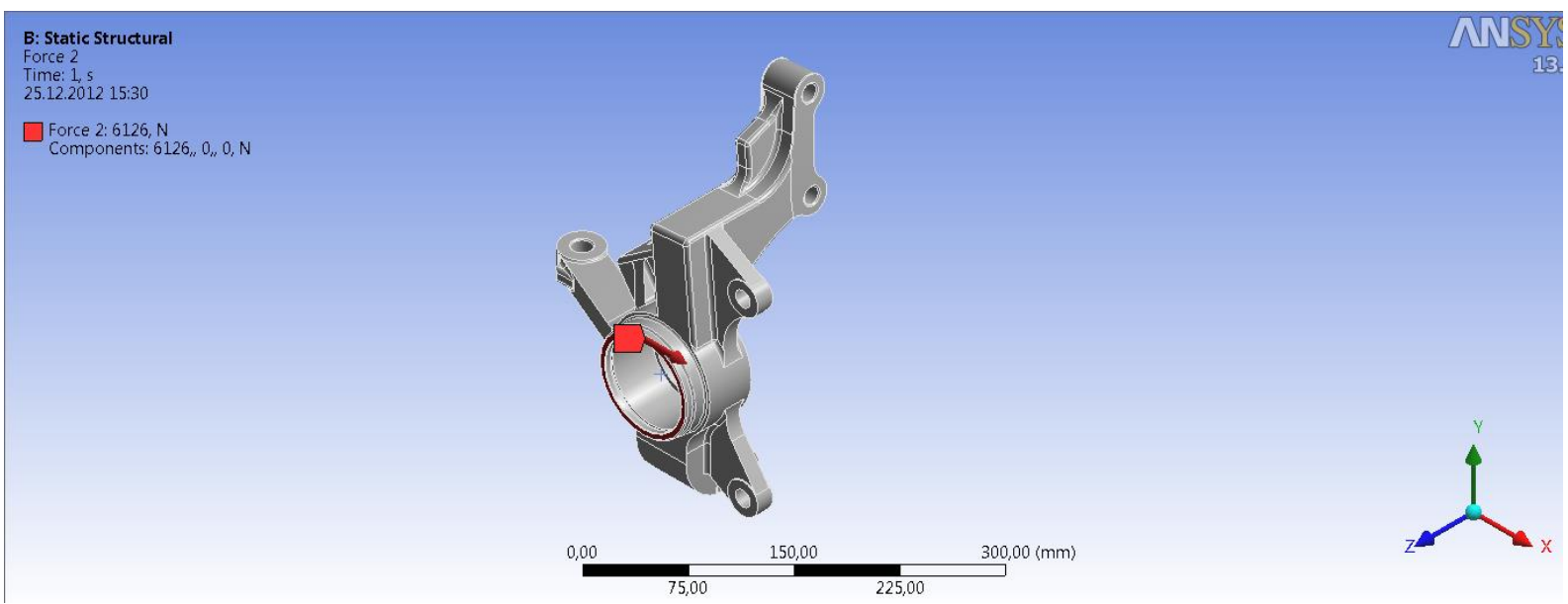

Şekil 5. Teğetsel kuvvet Fx in doğrultusu

\subsection{Kaygan Zemin Koşullart}

Tekerleklere gelen yatay yüklerin ( $\mathrm{Fy}, \mathrm{Fz}$ ) eşit olmasından kaynaklı yatay yük ve dikey reaksiyon kuvveti tarafindan meydana gelen torklar farklı yönlerdedir. Bu farklı yönlerdeki momentler sağ ve sol aksonların momentlerinin aynı olmaması sonucunu doğurur. Tekerlek aksonuna yatay yönde gelen eğilme momenti iç tekerlek aksonuna gelenden daha geniştir. Bu yüzden bu araştırmada daha büyük moment taşıyan yatay tekerlek aksonu incelenmiştir. Şekil 6'da gösterilmektedir [4].

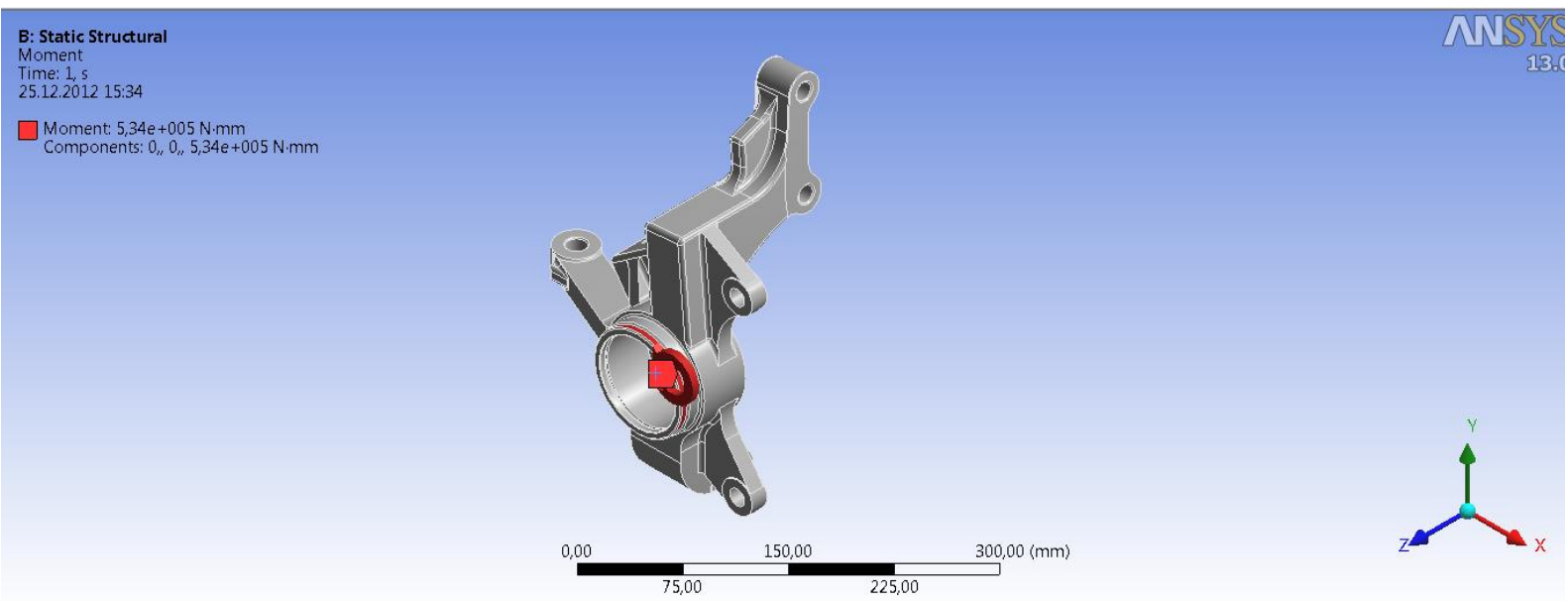

Şekil 6. Eğilme momenti

Önceki çalışmalara dayanarak, üç çalışma koşulunda aksonun taşıdığı yükler Tablo 3.1'de gösterilmiştir. Koordinat ekseni araç koordinasyonuna uygun hale getirilmiştir ve dışarıdan gelen yükler lastik-yüzey etki noktasına uygulanmıştır.

Tablo 3.1: Üç çalışma koşulunda aksonun taşıdığı yükler [4]

\begin{tabular}{|l|cccc|}
\hline & $\mathrm{F}_{\mathrm{x}}(\mathrm{N})$ & $\mathrm{F}_{\mathrm{y}}(\mathrm{N})$ & $\mathrm{F}_{\mathrm{z}}(\mathrm{N})$ & $\begin{array}{c}\text { Fren Kaliper } \\
\text { Torku (N.m) }\end{array}$ \\
\hline 1.Yol koşulları & 0 & 0 & 14240 & 0 \\
2.Yol koşulları & 6126 & 0 & 6126 & 534 \\
\hline 3.Yol ksşulları & 0 & 7833 & 7833 & 267 \\
\hline
\end{tabular}




\section{Analiz Sonuçları}

Sonlu elemanlar analiz sonuçları aşağıda gösterilmiştir.

\subsection{Darbeli Yol Koşullarına Göre Yapılan Analiz Sonuçlart}

Darbeli yol koşullarında Şekil 7 de maksimum gerilme rotil yuvasında; rotil ile rotil yuvasının birleștiği noktada saptanmıștır. İç noktada maksimum gerilme $86,4 \mathrm{MPa}$ olarak tespit edilmiştir. Çıkan sonucun değerlendirilmesi ile elde edilen darbeli yük koşuluna göre statik emniyet faktörü 3,7 olarak bulunmuştur. Bu değer akma değeri olan $320 \mathrm{MPa}$ değerinin altındadır. Ancak analizde bulunan gerilme değeri bizi net sonuca ulaştırmaz. Araç hareket halinde iken bu maksimum gerilmenin oluştuğu noktaların yerini tespit etmek mümkün değildir. $\mathrm{Bu}$ nedenle alanda yorulma analizi yapmak gereklidir.
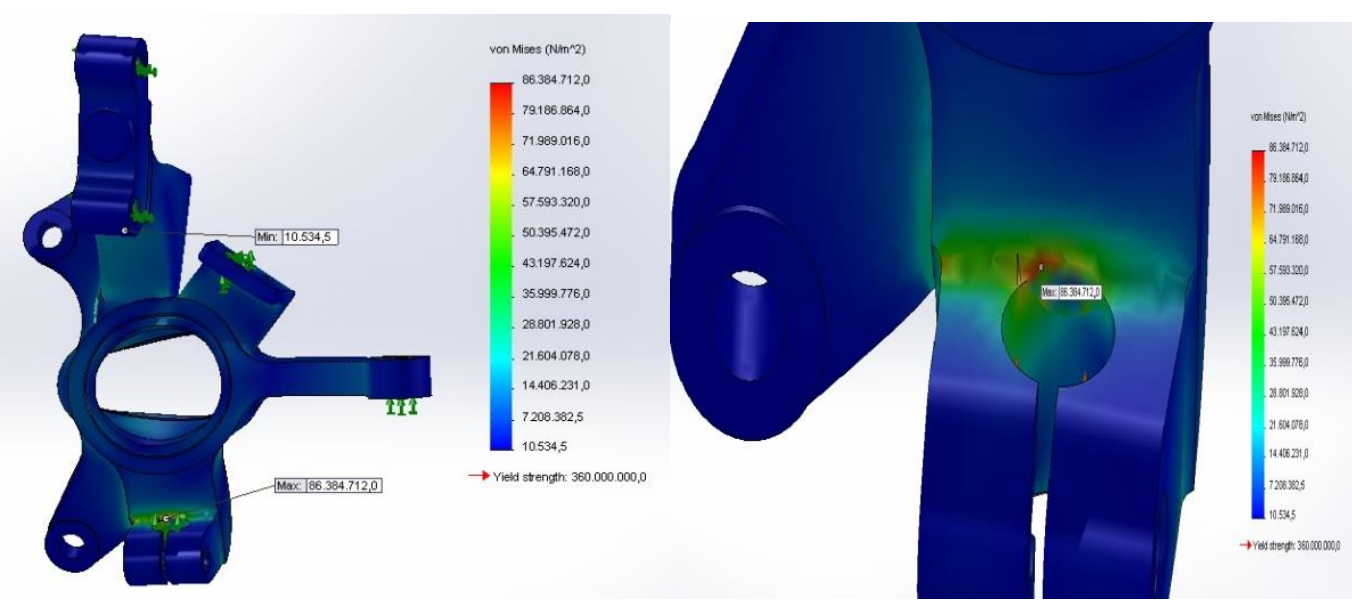

Şekil 7. Von Mises maksimum gerilme sonuçları

\subsection{Acil Fren Koșullarına Göre Yapılan Analiz Sonuçlart}

Acil fren koşullarında maksimum gerilme, akson ile amortisörün birleşme kolu kökünde meydana gelmektedir. Şekil 8'de meydana gelen maksimum gerilme değeri olan 109,2 MPa değeri

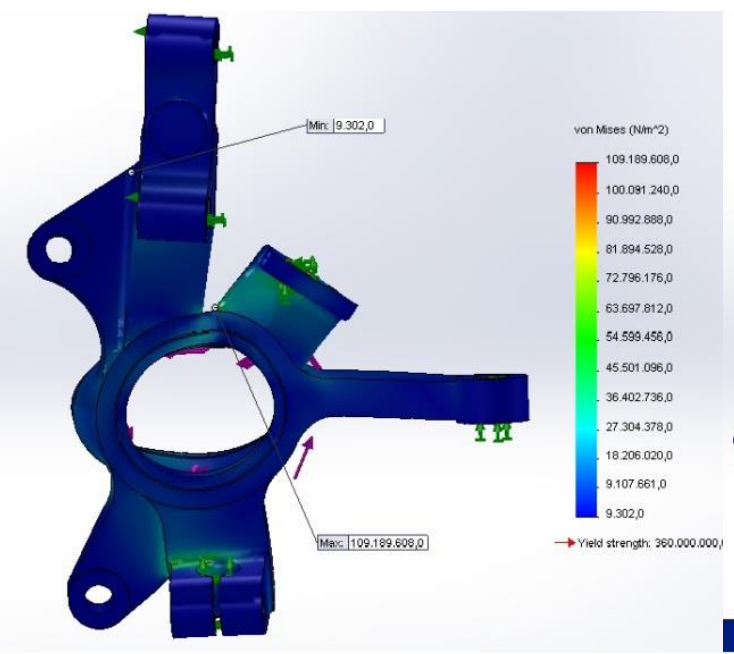

Şekil 8. Acil fren koşuluna göre elde edilen von Mises gerilme sonuçları gösterilmiştir. $\mathrm{Bu}$ gerilme de akma gerilmesi olan $320 \mathrm{MPa}$ 'dan düşüktür. Acil fren koşuluna göre ise statik emniyet faktörü 2,9 olarak elde edilmiştir. Burada da problemin yapısal bir sorunu yoktur. Asıl araştırılması gereken konu yorulma kayıpları ve gerilmeleridir.

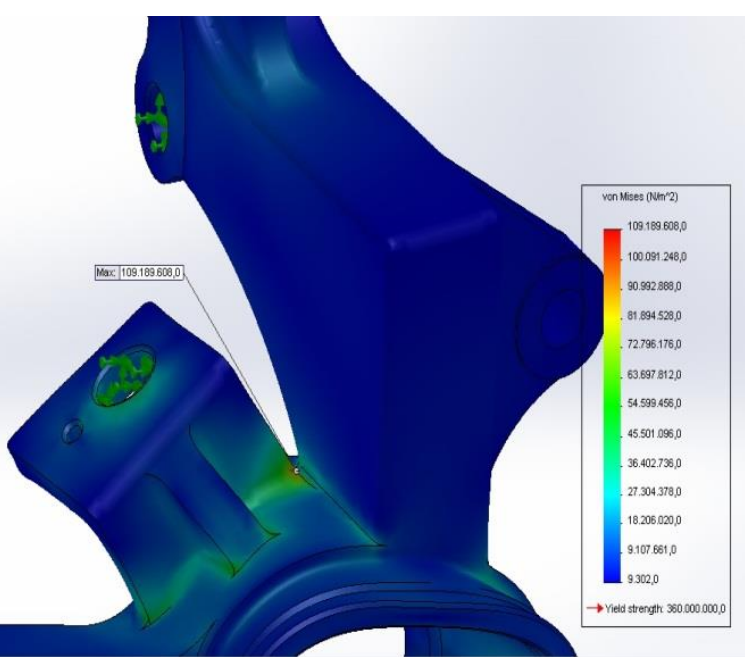




\subsection{Kaygan Zemin Koşullarına Göre Yapılan Analiz Sonuçları}

Kaygan zemin koşullarında maksimum gerilme rotil yuvasında, rotil ile aksonun birleştiği yatağın kökünde oluşmaktadır. Bu noktada ölçülen maksimum gerilme değeri. Şekil 9'da görüldüğü gibi 43,7 MPa olarak tespit edilmiştir. Bu gerilme değeri de akma değeri olan $320 \mathrm{MPa}$ değerinden daha büyük değildir. Kaygan zemin koşullarına göre ise statik emniyet faktörü 7,3 olarak elde edilmiştir. Yapılan bu analizde dinamik koşulun herhangi bir anı dikkate alınmıştır. Hızla değişen dinamik koşullar göz önüne alındığında maksimum gerilme noktasını tespit etmek doğal olarak mümkün olmayacaktır. Bu analizin de yorulma koşulları göz önüne alınarak yapılması asıl problemin çözümü için daha sağlıklı olacaktır.

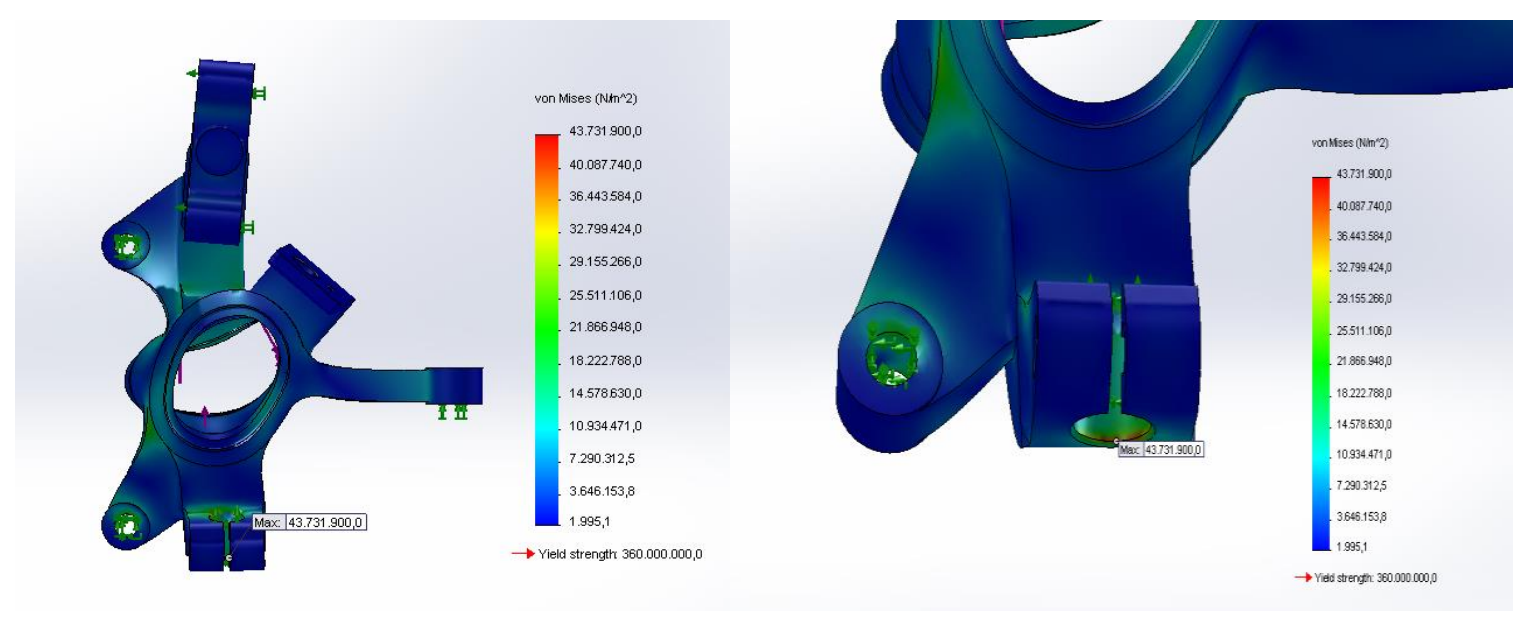

Şekil 9. Kaygan zemin koşullarına göre elde edilen von Mises gerilme sonucu

\section{Sonuç}

Yapılan bu çalışmada aksonun sınır koşullarda analizinde, maksimum gerilmenin acil fren koşullarında 109,2 $\mathrm{MPa}$ olarak tespit edildiği görülmüştür. $\mathrm{Bu}$ değer seçilen malzeme olan QT500-7 küresel dökme demir malzemesinin akma sınırı olan $320 \mathrm{MPa}$ değerinden ve genel anlamda çelik ve dökme demir malzemelerin akma sınırı değerlerinden düşüktür. Sistem analizi acil fren koşullarına göre değerlendirildiğinde statik emniyet faktörü 2.9 olarak elde edilmiştir. Bu durumda akson tasarım gerekliliklerini yerine getirmektedir. Karşılaştırma yapılan akson modeli ile bu model arasında parametre farklılıkları nedeniyle maksimum gerilmelerin oluştuğu bölgelerde farklılık olduğu görülmüştür. Bu farklılıklar değerlendirildiğinde kendi modelimizin karşılaştırması yapılan diğer modele göre daha güvenli olduğu görülmüştür. Çalışma koşulları ağırlaştığında maksimum gerilmelerin hangi bölgelerde çıkacağını öngörmek mümkün değildir. Akson çok eksenli dinamik yüklere maruz kalabilir. Normal şartlar altında aksonda hasarın yorulma olayı sonucunda gerçekleşeceği tahmin edilmiştir. $\mathrm{Bu}$ sonuçlar ışığı altında akson yorulma dayanımı yüksek malzemelerden imal edilmelidir.

\section{Kaynaklar}

[1] Wang Hongwei, Han Guoli. Reliability Analysis of Mine Automobile Steering Joint Based on ANSYS. Coal Mine Machinary. Vol.128 No.14 Apr. 2007 pp: 109-111. (in Chinese)

[2] M Zoroufi and A Fatemi. Experimental durability assessment and life prediction of vehicle suspension components: a case study of steering knuckles. Source: Proceedings of the Institution of Mechanical Engineers, Part D: Journal of Automobile Engineering, vol. 220, no 11, pp: 1565-1579, 2006.

[3] Wang Hongwei, Huang Wenbin. Forging process simulation of steering joint based on finite deformation theory. Journal of Plasticity Engineering. Vol.14 No.15, 2007.10:76-78. (in Chinese)

[4] Fan Pingqing, Zhao Bo, Qiu Long, The Analysis on Destruction Forms of Steering Knuckle 2011 Third International Conference on Measuring Technology and Mechatronics Automation. No.11. pp: 57-58. 2005 (in Chinese) 